\title{
Downregulation of P16 promotes cigarette smoke extract-induced vascular smooth muscle cell proliferation via preventing G1/S phase transition
}

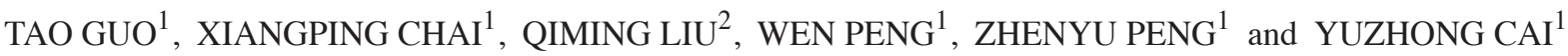 \\ Departments of ${ }^{1}$ Emergency Medicine and ${ }^{2}$ Cardiology, \\ The Second Xiangya Hospital of Central South University, Changsha, Hunan 410011, P.R. China
}

Received November 7, 2015; Accepted December 9, 2016

DOI: $10.3892 / e t m .2017 .4468$

\begin{abstract}
The proliferation of vascular smooth muscle cells (VSMCs) serves an important role in cigarette smoking-associated vascular diseases; however, the underlying mechanisms responsible for this remain unclear. The aim of the present study was to elucidate the role of P16 in cigarette smoke extract (CSE)-induced VSMC proliferation and the underlying mechanism responsible. Human aortic smooth muscle cells (HAOSMCs) were exposed to CSE, and an MTT assay and flow cytometry were performed to evaluate cell proliferation and cell cycle distribution. Western blotting was conducted to examine protein expression and bisulfite genomic sequencing polymerase chain reaction was used to determine the methylation status of the P16 promoter $\mathrm{CpG}$ island. It was demonstrated that treatment with CSE significantly promoted the proliferation of HAOSMCs in a concentration- and time-dependent manner and induced a downregulation in $\mathrm{P} 16$ expression (all $\mathrm{P}<0.05$ ). A luciferase reporter gene assay data demonstrated that CSE treatment induced hypermethylation of the P16 promoter, which led to a significant decrease in its transcriptional activity and significantly reduced P16 protein expression in HAOSMCs (both $\mathrm{P}<0.01$ ). Furthermore, P16 downregulation induced a significant increase in the expression of cyclin-dependent kinase (CDK) 4, CDK6 and phosphorylated retinoblastoma $(\mathrm{p}-\mathrm{Rb})$ protein (all $\mathrm{P}<0.001)$ and significantly increased the ratio of cells in $\mathrm{S}$ phase in CSE-treated HAOSMCs $(\mathrm{P}<0.001)$. Overexpression of P16 inhibited CSE-induced cell proliferation through inducing cell cycle arrest in G1 phase $(\mathrm{P}<0.001)$, and led to decreased levels of CDK4 $(\mathrm{P}<0.01)$, CDK6 $(\mathrm{P}<0.01)$ and $\mathrm{p}-\mathrm{Rb}(\mathrm{P}<0.001)$ in HASMCs. The results of the present
\end{abstract}

Correspondence to: Professor Xiangping Chai, Department of Emergency Medicine, The Second Xiangya Hospital of Central South University, 139 Renmin Road, Changsha, Hunan 410011, P.R. China

E-mail: csuxiangpingchai@sina.com

Key words: cigarette smoke extract, vascular smooth muscle cells, proliferation, cell cycle, P16 study therefore demonstrate that P16 may be associated with the CSE-induced proliferation of VSMCs, suggesting that P16 serves a role in the development of cigarette smoke-associated vascular diseases.

\section{Introduction}

Cigarette smoking is widely recognized as a primary risk factor for cardiovascular diseases. For the year 2000, it was estimated that $>10 \%$ of cardiovascular mortality cases worldwide were attributable to smoking (1). The accumulated evidence of previous studies suggests that cigarette smoking results in atherosclerosis, which is the main pathological characteristic of smoking-associated peripheral vascular diseases, coronary heart diseases, cerebral vascular diseases and aortic aneurysm $(2,3)$. Abnormal proliferation of vascular smooth muscle cells (VSMCs) is considered to be an important event in the development of atherosclerosis (4); however, the pathogenesis of cigarette smoking-induced VSMC proliferation remains unclear.

Cell cycle progression is vital to cell proliferation (5) and is a highly regulated process involving a complex cascade of events, including the activation of cyclin-dependent kinases (CDKs) (6). For example, extracellular signals induce cyclin D1 expression, which activates CDK4 and CDK6 (7). These activated CDKs induce phosphorylation of retinoblastoma protein $(\mathrm{Rb})$, causing it to dissociate from transcription factors such as members of the E2F family, which then activate various genes associated with cell cycle progression to $S$ phase (8). Therefore, CDK4 and CDK6 serve a crucial role in regulating cell cycle progression from $\mathrm{G} 1$ phase to the $\mathrm{S}$ phase.

P16 is a CDK inhibitor, which inhibits CDK4 and CDK6 activation and their downstream Rb-E2F signaling, thereby preventing cell cycle progression from G1 to $S$ phase (9). Previous studies have demonstrated that P16 serves an important role in the regulation of VSMC proliferation; for example, P16 was found to participate in the process of peroxisome proliferator-activated receptor (PPAR) $\alpha$-inhibited VSMC proliferation $(10,11)$. Additionally, it has been demonstrated that various genetic and epigenetic abnormalities, including mutations and hypermethylation, may be associated with the development and progression of atherosclerosis (12). Epigenetic 
silencing of some key genes, such as P16, appears to be a critical event in the development of cardiovascular diseases (13). However, the roles of P16 in cigarette smoking-induced proliferation of VSMCs remain to be fully elucidated; therefore, in the present study, the expression of P16 and its downstream signal molecules, and its roles in the proliferation of cigarette smoke extract (CSE)-treated VSMCs were investigated.

\section{Materials and methods}

Cell Culture. Human aortic smooth muscle cell (HAOSMC) line was obtained from the Shanghai Institute for Biological Sciences, Chinese Academy of Sciences (Shanghai, China) and maintained in Dulbecco's Modified Eagle Medium (DMEM; MP Biomedicals, LLC, Santa Ana, CA, USA) 10\% fetal bovine serum supplemented with $100 \mathrm{U} / \mathrm{ml}$ penicillin and $100 \mu \mathrm{g} / \mathrm{ml}$ streptomycin at $37^{\circ} \mathrm{C}$ in an atmosphere containing $5 \% \mathrm{CO}_{2}$. A total of $2 \mathrm{ml}$ HAOSMCs $\left(2 \times 10^{5}\right.$ cells $\left./ \mathrm{ml}\right)$ were seeded in 6 -well plates. HASMCs were incubated in DMEM containing $0.2 \%$ bovine serum albumin (Wuhan Huamei Biotech Co., Ltd., Wuhan, China) at $37^{\circ} \mathrm{C}$ for $24 \mathrm{~h}$, at which point the cells had reached $\sim 80 \%$ confluence.

CSE preparation. CSE was prepared according to the method previously described with a few modifications (12). Briefly, cigarettes (Fu-rong; Tobacco Hunan Industrial Corporation, Changsha, China) without filters were combusted and the smoke was passed through a filter to remove particles and bacteria. Smoke was subsequently collected in a tube containing PBS (1 ml per cigarette) using a vacuum pump. The CSE-PBS solution was freshly prepared for each set of experiments.

Measurement of P16 promoter CpG island methylation status by bisulfite genomic sequencing polymerase chain reaction $(P C R)$. Genomic DNA was extracted from HAOSMCs with or without CSE treatment by using a DNA Extraction kit according to the manufacturer's protocols (Takara Biotechnology Co., Dalian, China). After identification and quantification by UV spectrophotometry, genomic DNA ( $1 \mu$ g per sample) was modified with bisulfite using a CpGenome ${ }^{\mathrm{TM}}$ DNA Modification kit (Qiagen China Co., Ltd., Shanghai, China) according to the manufacturer's protocol, and the modified DNA was amplified using the following primers: P16, forward 5'-TTTTGTTTT TTAAATTTTTTGGAGG-3' and reverse 5'-AAACCCAAT CCTCCTTCCTTAC-3'. The PCR amplification conditions were as follows: $94^{\circ} \mathrm{C}$ for $3 \mathrm{~min}$, followed by 35 cycles of $94^{\circ} \mathrm{C}$ for $30 \mathrm{sec}, 55^{\circ} \mathrm{C}$ for $30 \mathrm{sec}$ and $72^{\circ} \mathrm{C}$ for $30 \mathrm{sec}$, and a final extension at $72^{\circ} \mathrm{C}$ for $7 \mathrm{~min}$. The PCR products were cloned into a T-vector and transformed into Escherichia coli cells (DH5 $\alpha$; MiaoLing Biological Technology Co., Ltd., Wuhan, China). Subsequently, the E. coli cells were inoculated in $100 \mu \mathrm{g} / \mathrm{ml} \mathrm{Ampicillin}{ }^{+} \mathrm{LB}$ agar plates, incubated at $37^{\circ} \mathrm{C}$ for 12-16 $\mathrm{h}$ and then five independent clones were sequenced for the amplified fragment by Shenzhen Huada Gene Technology Co., Ltd. (Shenzhen, China). The demethylation rate of the $\mathrm{CpG}$ pairs in the HAOSMC with or without of $5 \mu \mathrm{mol} / 15-\mathrm{Zac}$ was calculated from the sequencing results.

Luciferase reporter gene assays. The P16 promoter region was ligated into the pGL3-enhancer vector (Promega Corporation,
Madison, WI, USA) generating pGL3-basic-P16 (pGL3-P16), performed by Shanghai GenePharma Co., Ltd. (Shanghai, China). All vector sequences were confirmed by DNA sequencing. Cells were transfected with the pGL3-P16 reporter plasmid, stored at $4^{\circ} \mathrm{C}$ for $24 \mathrm{~h}$ and treated with $2.5 \% \mathrm{CSE}$ or co-treated with $2.5 \% \mathrm{CSE}$ and $15 \mathrm{nM}$ 5'-Aza-deoxycytidine (5-Aza; Sigma-Aldrich; Merck Millipore, Darmstadt, Germany) and stored at $4^{\circ} \mathrm{C}$ for $24 \mathrm{~h}$. Normal control (NC) cells were treated with $0.1 \mathrm{M}$ PBS. Cells were subsequently collected and total proteins were isolated using lysis buffer (Beyotime Institute of Biotechnology, Haimen, China). Lysates were separated by centrifugation at $12,000 \mathrm{x} \mathrm{g}$ for $10 \mathrm{~min}$ at $4^{\circ} \mathrm{C}$. Then, $10 \mathrm{ml}$ of the supernatants were used to detect luciferase activities using luciferase reporter gene assay kit (BioVision, Inc., Milpitas, CA, USA) on a microplate luminometer.

Cell transfection and small interfering (si)RNA. P16INK4a siRNA, P16INK4a overexpression plasmid and transfected reagents were purchased from Shanghai GenePharma Co., Ltd. For the transfections, HAOSMCs were seeded onto 6 -well plates and allowed to reach $60 \%$ confluence on the day of transfections. Transfections were performed with a Lipofectamine ${ }^{\circledR} 2000$ kit (Shanghai GenePharma Co., Ltd.) according to the manufacturer's protocols. A total of $50 \mathrm{nM}$ empty plasmid, expression plasmid, P16INK4a overexpression plasmid (GenePharma Biotechnology) or P16INK4a siRNA were transfected into HAOSMCs. The siRNA sequence used was as follows: Forward, 5'-CCCAACGCACCGAAUAGU UTT-3' and reverse, 5'-AACUAUUCGGUGCGUUGGGTT-3'. Cells were harvested $48 \mathrm{~h}$ post-transfection.

MTT assay. Cell growth was determined using MTT kits (Beyotime Institute of Biotechnology) according to published protocols (14). HAOSMCs were re-seeded into 96-well plates ( $2 \times 10^{3}$ cells/well) following $24 \mathrm{~h}$ of treatment with different concentrations $(0,1,2.5,5$ and $10 \%)$ of CSE and continuously cultured for one, two, three or four days. Absorbance at $490 \mathrm{~nm}$ was measured using a plate reader (Thermo Fisher Scientific, Inc., Waltham, MA, USA).

Ethynyl deoxyuridine (EdU) incorporation analysis. Cell proliferation was measured using an EdU assay kit (Wuhan Huamei Biotech Co., Ltd.), according to the manufacturer's protocols. Briefly, HAOSMCs were seeded at $4 \times 10^{3}-1 \times 10^{5}$ cells per well in 96-well plates in triplicate and transfected with $50 \mathrm{nM}$ P16 overexpression vector, P16 siRNA expression vector or their corresponding control, respectively. Cells were stored for $48 \mathrm{~h}$ and incubated with $50 \mu \mathrm{M} \mathrm{EdU}$ for $4 \mathrm{~h}$ at $37^{\circ} \mathrm{C}$, followed by $4 \%$ formaldehyde for $15 \mathrm{~min}$ at room temperature. Cells were subsequently permeabilized with $0.5 \%$ Triton X-100 for $20 \mathrm{~min}$ at room temperature, washed three times with PBS and treated with $100 \mu \mathrm{l} /$ well of 1x Apollop reaction cocktail (Wuhan Huamei Biotech Co., Ltd.) at room temperature for $30 \mathrm{~min}$. DNA was stained with $100 \mu \mathrm{l}$ of Hoechst 33342 $(5 \mu \mathrm{g} / \mathrm{ml})$ at $4^{\circ} \mathrm{C}$ for $30 \mathrm{~min}$ and visualized using a fluorescence microscope (Olympus Corporation, Tokyo, Japan).

Flow cytometry. Briefly, $\sim 3 \times 10^{6}$ cells were seeded in 6-well plates, stored at $4^{\circ} \mathrm{C}$ for $14 \mathrm{~h}$ and treated with $2.5 \% \mathrm{CSE}$ with 
or without P16 expression plasmid or P16 siRNA plasmid. Cells were harvested at $8 \mathrm{~h}$ post-transfection and fixed in $70 \%$ ice-cold ethanol at $4^{\circ} \mathrm{C}$ for $24 \mathrm{~h}$. Following the treatment, cultured cells were trypsinized and washed with PBS twice, and subsequently permeabilized with $0.05 \%$ Triton X-100 in PBS for $10 \mathrm{~min}$. The permeabilized cells were stained with $10 \mu \mathrm{g} / \mathrm{ml}$ propidium iodide solution for $10 \mathrm{~min}$ in a dark box. Finally, the different phases of the cell cycle were analyzed using FACS analysis (BD FACSCalibur; BD Biosciences, Franklin Lakes, NJ, USA).

Western blot analysis. Cell lysates were prepared as previously described (15). A total of $20 \mu \mathrm{g}$ protein per lane was separated on a $12 \%$ SDS-PAGE gel and transferred onto polyvinylidene fluoride membranes. Membranes were blocked with Tris-buffered saline (10 mM Tris, $\mathrm{pH} 7.5 ; 100 \mathrm{mM}$ $\mathrm{NaCl}$ ) plus $0.1 \%$ Tween-20 containing 5\% dry skimmed milk for $45 \mathrm{~min}$ and incubated with primary antibodies of CDK4 (PA11659A0Rb, 1:200), CDK6 (PA564539, 1:100), P16INK (PA051713, 1:1,000), p-Rb (PA201739, 1:1,000) and GAPDH (PA00025C0Rb, 1:1,000) (all from Wuhan Huamei Biotech Co., Ltd.) overnight at $4^{\circ} \mathrm{C}$. Membranes were washed three times with PBS and incubated with horseradish peroxidase-conjugated goat anti-rabbit secondary antibody (MA000071M0m, 1:4,000; Wuhan Huamei Biotech Co., Ltd.) for $2 \mathrm{~h}$ at room temperature. The immunoreaction was visualized using the enhanced chemiluminescence reagents. CDK4, CDK6, $\mathrm{p}-\mathrm{Rb}$ and P16INK bands were quantified by scanning densitometry using the Molecular Imager ChemiDoc X-Ray Spectroscopy System (Bio-Rad Laboratories, Inc., Hercules, CA, USA) and normalized to GAPDH. The experiment was performed in three replicates.

Statistical analysis. Data were analyzed using SPSS v.17.0 software package (SPSS Inc., Chicago, IL, USA). Pearson's correlation was used to evaluate the association between P16 expression and cell proliferation. One-way analysis of variance was used to analyze measurement data and a least significant differences t-test was used for comparisons between groups. $\mathrm{P}<0.05$ was considered to indicate a statistically significant difference.

\section{Results}

CSE treatment promotes the viability and proliferation of HASMCs and decreases the P16 protein expression in HAOSMCs. MTT assay revealed that the viability of HAOSMCs significantly increased following treatment with 1-10\% CSE compared with the NC group, with a peak at 2.5\% CSE $(\mathrm{P}<0.01$; Fig. 1A). HAOSMCs were treated with $2.5 \%$ CSE for $0,12,24,36$ or $48 \mathrm{~h}$ and MTT assay demonstrated that this significantly induced cell viability with a peak at $24 \mathrm{~h}(\mathrm{P}<0.001$; Fig. 1B). Additionally, the Edu assay demonstrated that CSE treatment was able to significantly increase the proportion of Edu positive cells compared with the NC group, with a peak at $24 \mathrm{~h}(\mathrm{P}<0.01$; Fig. $1 \mathrm{C})$. Western blot analysis demonstrated that $\mathrm{P} 16$ protein expression was markedly decreased following $12 \mathrm{~h} 2.5 \%$ CSE treatment, with the largest decrease at $24 \mathrm{~h}(\mathrm{P}<0.001$; Fig. 1D). Pearson's correlation analysis demonstrated that P16 expression was negatively correlated with the ratio of Edu positive cells in HAOSMCs at all time points $(\mathrm{P}=0.002$; Fig. 1E), indicating that $\mathrm{CSE}$ induces HAOSMC proliferation in a dose- and time-dependent manner and is associated with P16 expression.

CSE treatment induces $P 16$ promoter hypermethylation in HAOSMCs. To investigate whether P16 silencing in CSE-treated HAOSMCs was caused by promoter methylation, genomic DNA from was extracted from HAOSMCs treated with or without CSE to perform bisulfite genomic sequencing polymerase chain reaction. It was demonstrated that the P16 promoter was hypermethylated in HAOSMCs treated with CSE, particularly at the sites $-786,-676,-31,+7$ and +32 (Fig. 2A). Additionally, it was demonstrated that CSE was able to significantly reduce P16 promoter activity, and this effect was significantly reversed by demethylation agent 5-Aza (both $\mathrm{P}<0.01$; Fig. 2B). Furthermore, CSE treatment was able to markedly reduce P16 expression, whereas CDK4, CDK6 and p-Rb expressions were markedly increased (Fig. 2C). Treatment with 5-Aza counteracted the CSE mediated-downregulation of P16 protein, and reversed the increased protein levels of CDK4, CDK6 and p-Rb (Fig. 2C). These results indicate that the downregulation of P16 in HAOSMCs treated with CSE is associated with its promoter hypermethylation.

Downregulation of P16 enhances CSE-mediated cell proliferation and cell cycle arrest in HAOSMCs. To investigate the role of P16 in HAOSMC proliferation, expression of P16 was significantly knocked down at mRNA and protein levels (both $\mathrm{P}<0.001$; Fig. 3A and B). The results of the MTT assay demonstrated that P16 downregulation significantly enhanced CSE-induced viability compared with scramble group $(\mathrm{P}<0.01$; Fig. 3C) and significantly increased the ratio of Edu positive cells compared with scramble group $(\mathrm{P}<0.01$; Fig. 3D). The transition from G1 phase to $\mathrm{S}$ phase is the earliest event in cell cycle progression and serves an important role in cell proliferation. Flow cytometry revealed that the ratio of cells in G0/G1 phase was significantly decreased following P16 knockdown compared with the scramble group, whereas the ratio of cells in $\mathrm{S}$ phase was significantly increased compared with the scramble group $(\mathrm{P}<0.001$; Fig. 3E). To explore the mechanism by which downregulation of P16 influences CSE-induced proliferation, CDK4, CDK6, and $\mathrm{p}-\mathrm{Rb}$ protein expression were assessed. Protein levels of CDK4, CDK6 and p-Rb were significantly increased in HAOSMCs co-treated with $2.5 \%$ CSE and siRNA P16 transfection (all P<0.001; Fig. 3F).

Overexpression of P16 reverses CSE-stimulated cell proliferation and cell cycle progression in HAOSMCs. To further illustrate the role of P16 on HAOSMC proliferation, the overexpression of P16 at mRNA and protein levels was induced (Fig. 4A and B). As illustrated in Fig. 4C and D, overexpression of P16 significantly inhibited CSE-induced viability and reduced the ratio of Edu positive cells compared with the empty vector $(\mathrm{Ev})$ group $(\mathrm{P}<0.01)$. The result of flow cytometry demonstrated that overexpression of P16 significantly increased the ratio of cells in G0/G1 phase and also reduced the ratio of cells in $\mathrm{S}$ phase compared with the Ev group ( $\mathrm{P}<0.001$; Fig. 4E). CDK4, CDK6, and $\mathrm{p}-\mathrm{Rb}$ protein levels were significantly decreased in HAOSMCs co-treated 
A

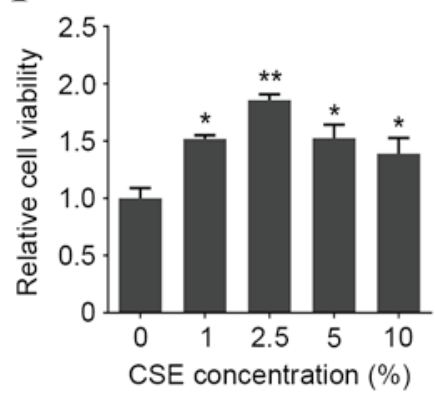

$\mathrm{D}$

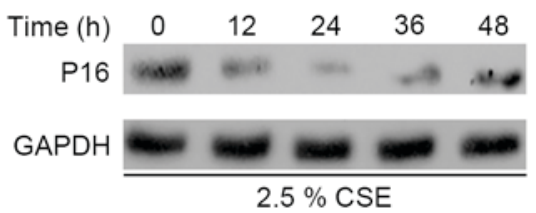

$\mathrm{B}$
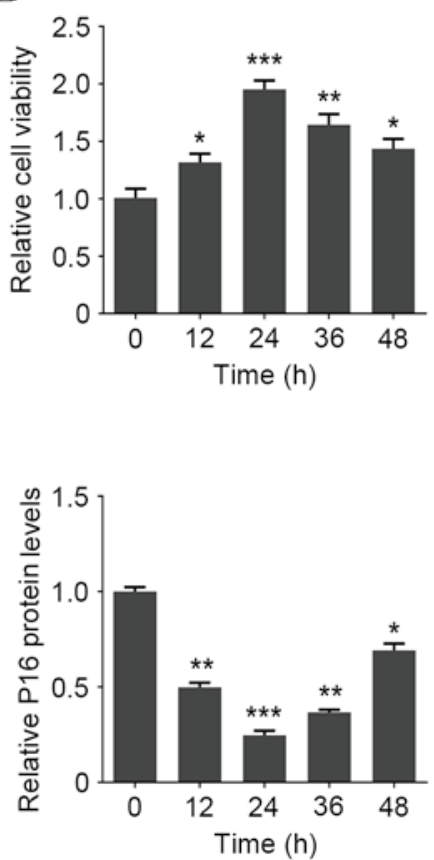

$\mathrm{C}$

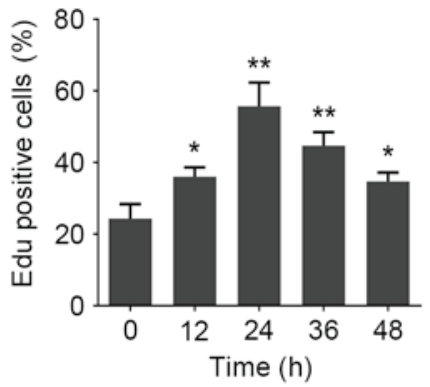

$\mathrm{E}$

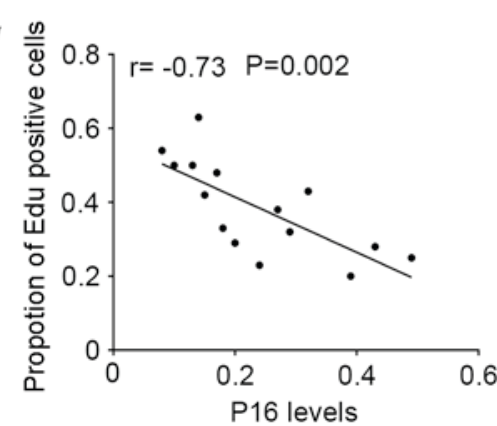

Figure 1. CSE increases cell viability and proliferation in a dose and time-dependent manner, and reduces P16 expression in a time dependent manner in HAOSMCs. (A) Cell viability following treatment with CSE. (B) Cell viability following treatment with $2.5 \%$ CSE for different durations. (C) Percentage of Edu-positive cells following treatment with 2.5\% CSE for different durations. (D) Western blot analysis of P16 expression in cells following treatment with $2.5 \%$ CSE for different durations. (E) Pearson's correlation analysis of P16 expression and proliferation rate. Data are expressed as the mean \pm standard deviation. $\mathrm{n}=3,{ }^{*} \mathrm{P}<0.05,{ }^{* *} \mathrm{P}<0.01,{ }^{* * *} \mathrm{P}<0.001$ vs. NC group. CSE, cigarette smoke extract; HASMC, human aortic smooth muscle cells; Edu, ethynyl deoxyuridine.
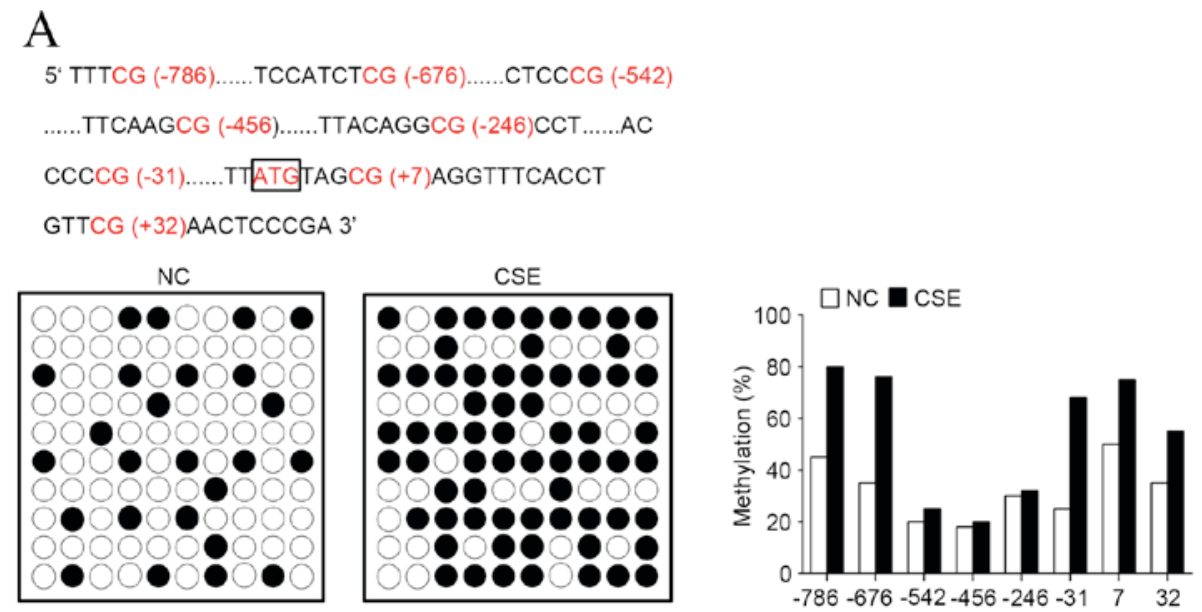

$\mathrm{B}$

$\mathrm{C}$
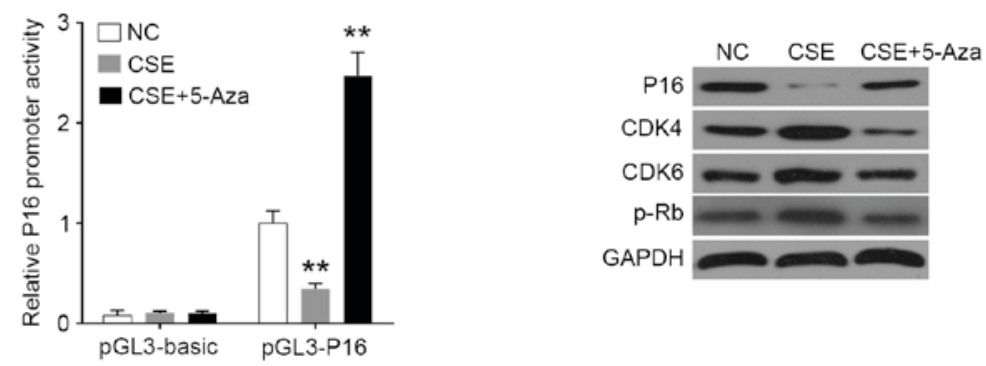

Figure 2. CSE induces hypermethylation of P16 promoter. (A) P16 promoter was hypermethylated by CSE treatment, most markedly at sites $-786,-676,-31,+7$ and +32 . (B) Luciferase reporter gene assay was used to detect the promoter activity of P16 following treatment with CSE or 5-Aza. (C) Western blot analysis of P16, CDK4, CDK6 and p-Rb levels following treatment with CSE or 5-Aza. Data are expressed as the mean \pm standard deviation. $\mathrm{n}=3,{ }^{*} \mathrm{P}<0.05,{ }^{* *} \mathrm{P}<0.01$, ${ }^{* * * *} \mathrm{P}<0.001$ vs. NC group. CSE, cigarette smoke extract; Aza, azactadine; CDK, cyclin-dependent kinase; p-Rb, phosphorylated retinoblastoma protein; NC, negative control. 
A

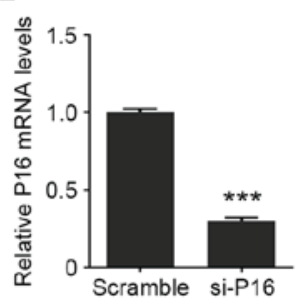

D

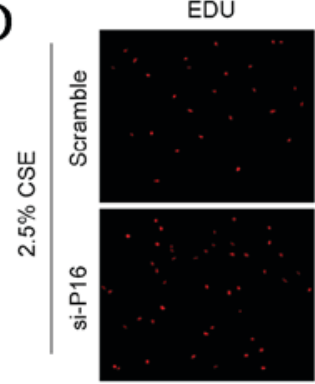

B

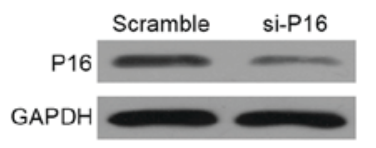

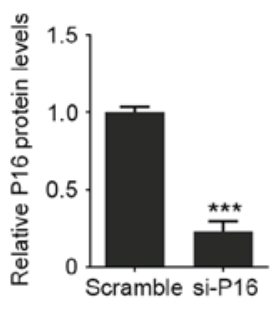

C

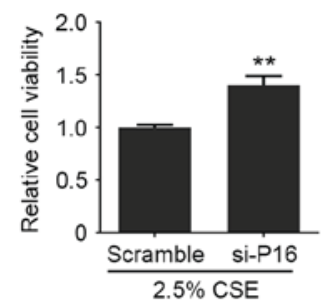

$\mathrm{E}$
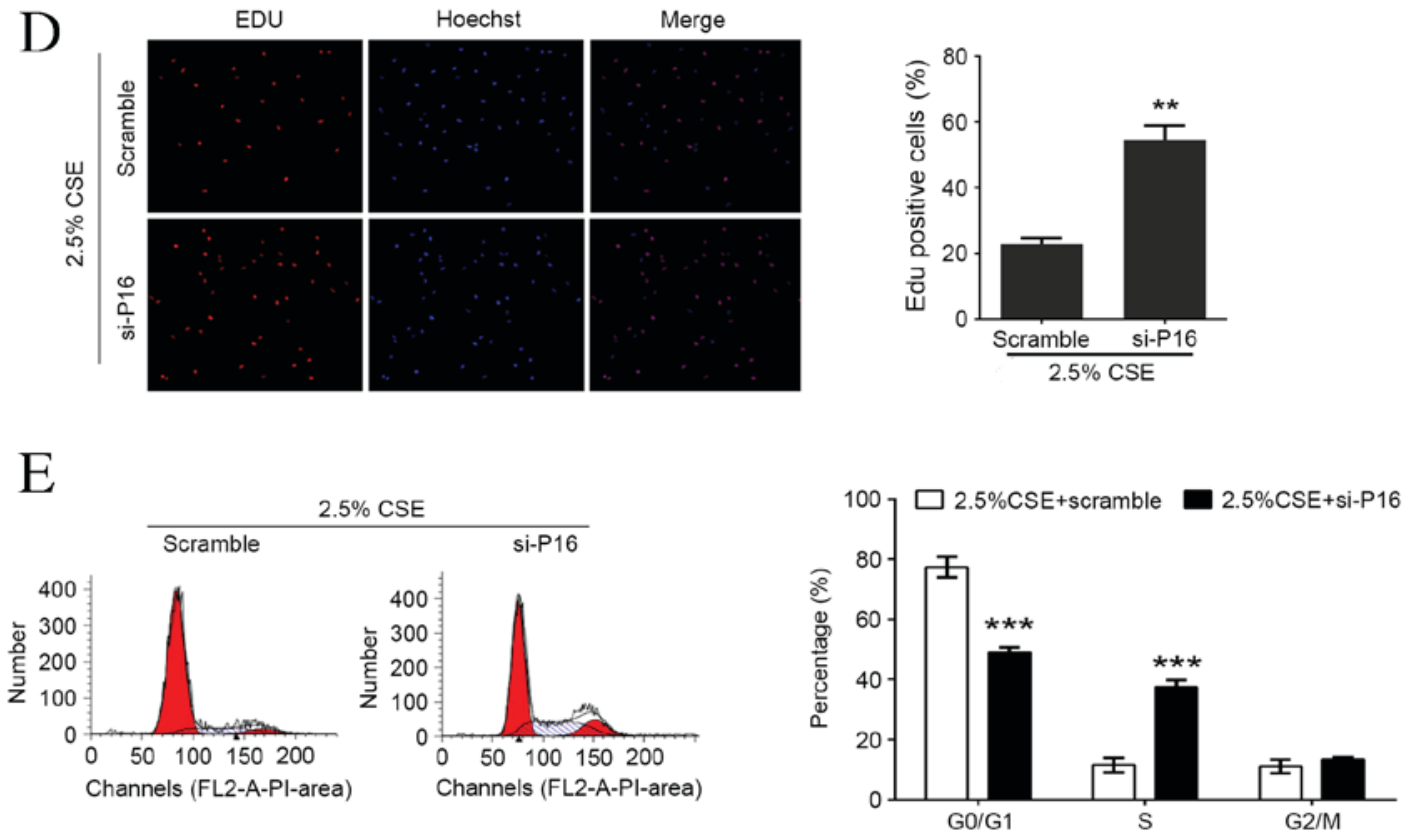

F
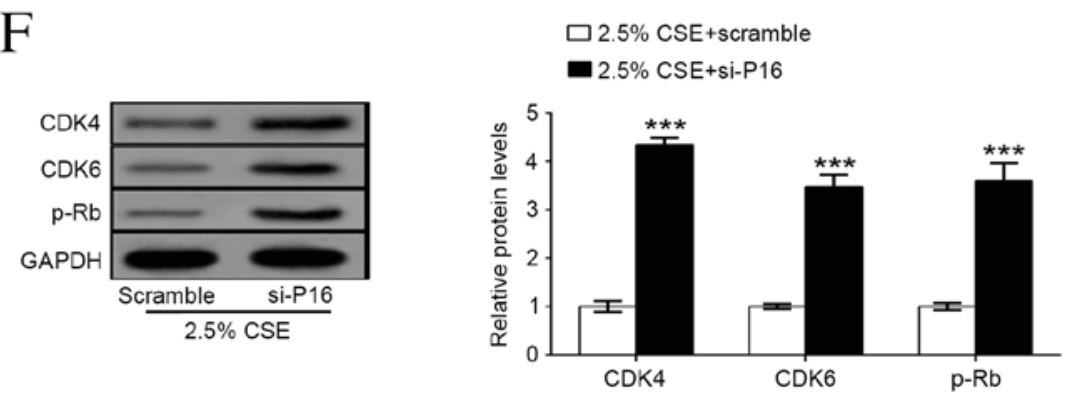

Figure 3. Downregulation of P16 enhances CSE-mediated cell proliferation and cell cycle arrest in human aortic smooth muscle cells. (A) P16 mRNA levels following transfection with scramble or siRNA P16. (B) P16 protein levels following transfection with scramble or siRNA P16. (C) Cell viability detection following P16 knockdown and 2.5\% CSE treatment. (D) Percentage of Edu positive cells following P16 knockdown and 2.5\% CSE treatment. (E) Representative flow cytometry and the percentage of cells in each cell cycle phase following P16 knockdown and 2.5\% CSE treatment. (F) Western blot analysis of P16, CDK4, CDK6 and p-Rb levels following P16 knockdown and 2.5\% CSE treatment. Data are expressed as the mean \pm standard deviation. $\mathrm{n}=3,{ }^{*} \mathrm{P}<0.05,{ }^{* *} \mathrm{P}<0.01,{ }^{* * *} \mathrm{P}<0.001$ vs. scramble group. CSE, cigarette smoke extract; si, small interfering; Edu, ethynyl deoxyuridine; CDK, cyclin-dependent kinase; $\mathrm{p}-\mathrm{Rb}$, retinoblastoma protein.

with $2.5 \%$ CSE and P16 expressed vector compared with the Ev group (CDK4 and CDK6, $\mathrm{P}<0.01$; p-Rb, $\mathrm{P}<0.001$; Fig. 4F).

\section{Discussion}

It has been well documented that cigarette smoking is able to cause atherosclerosis via the mechanisms of endothelial dysfunction, inflammation, and VSMC proliferation (2). Although the molecular mechanisms driving VSMC proliferation have been investigated (16), they remain unclear. The present study demonstrated that CSE was able to stimulate VSMC proliferation via downregulating the P16 expression by inducing P16 promoter hypermethylation, upregulating the expression of P16 downstream signal molecules and blocking cell cycle progression from $\mathrm{G} 1$ to $\mathrm{S}$ phase.

$\mathrm{P} 16$ is an inhibitor of CDKs and an important regulator of cell cycle progression in malignant tumor cells (9). Downregulation of P16 leads to a loss of cell cycle control, which promotes malignant cell proliferation $(17,18)$. In a previous study, $\mathrm{P} 16$ was found to be overexpressed in VSMCs of aging mice, which may modify 
A

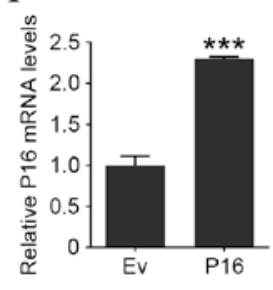

$\mathrm{B}$

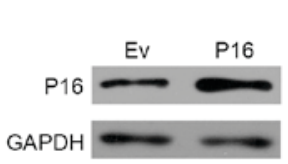

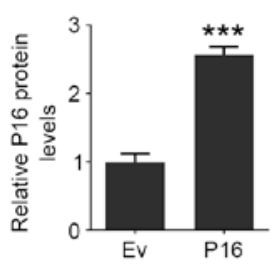

$\mathrm{C}$

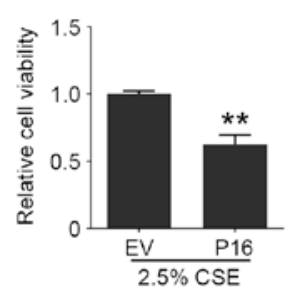

$\mathrm{D}$

Edu

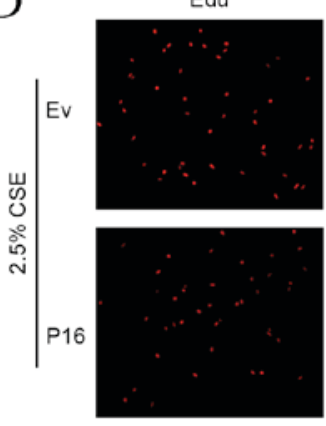

Hochest
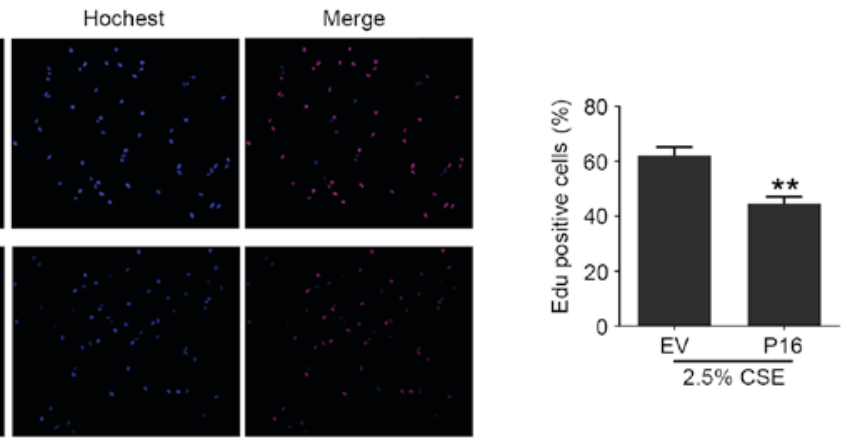

$\mathrm{E}$

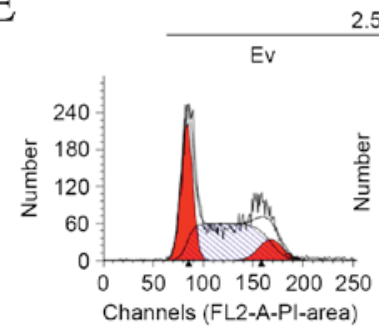

2.5\% CSE
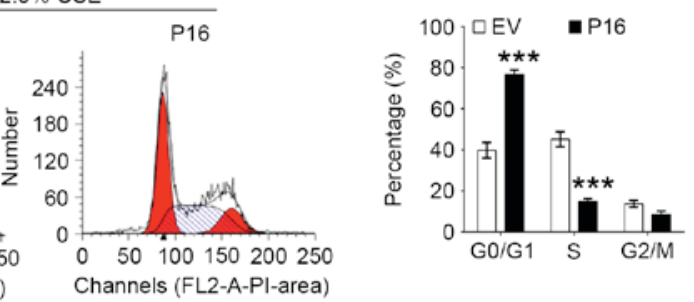

F

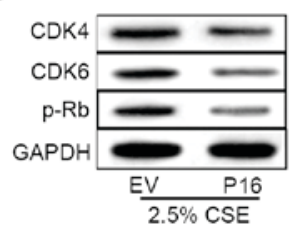

$2.5 \% \mathrm{CSE}$

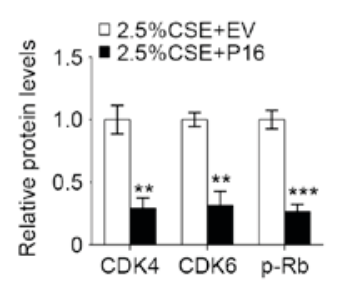

Figure 4. Upregulation of P16 reverses CSE-induced cell proliferation and cell cycle arrest in human aortic smooth muscle cells. (A) P16 mRNA levels following Ev and P16-expressed plasmid transfection. (B) P16 protein levels following Ev and P16-expressed plasmid transfection. (C) Cell viability following P16 overexpression and 2.5\% CSE treatment. (D) Percentage of Edu positive cells following P16 overexpression and 2.5\% CSE treatment. (E) Representative flow cytometry and the percentage of cells in each cell cycle phase following P16 overexpression and 2.5\% CSE treatment. (F) Western blot analysis of P16, CDK4, CDK6 and p-Rb levels following P16 overexpression and 2.5\% CSE treatment measured by western blotting. Data are expressed as the mean \pm standard deviation. $\mathrm{n}=3,{ }^{*} \mathrm{P}<0.05,{ }^{* *} \mathrm{P}<0.01,{ }^{* * *} \mathrm{P}<0.001$ vs. Ev group. CSE, cigarette smoke extract; Ev, empty vector; Edu, ethynyl deoxyuridine; CDK, cyclin-dependent kinase; $\mathrm{p}-\mathrm{Rb}$, phosphorylated retinoblastoma protein.

VSMC response to injury and stress and therefore accelerate the development of age-related cardiovascular diseases (10). P16 has also been demonstrated to participate in the course of PPAR $\alpha$-inhibited VSMC proliferation (11). It was reported that DNA methylation levels at p15 (INK4b) was significantly increased in patients with coronary artery disease (CAD), which was prevalent in the lymphocytes, and there was a stepwise increase in p15 (INK4b) and p16 (INK4a) methylation as levels of antisense non-coding RNA in the INK4 locus (ANRIL) exon 1-5 expression were elevated (19). Miki et al (20) demonstrated that the methylation status of the P16 gene was important in the regulation of angiogenesis associated with progression of lung cancer via regulating vascular endothelial growth factor expression. The results of the present study demonstrated that P16 expression in HAOSMCs decreased following treatment with CSE in a concentration and time-dependent manner, caused by hypermethylation of the promoter and inhibition of promoter activity. Furthermore, Pearson's correlation analysis revealed a negative correlation between P16 protein expression and cell proliferation.

It has previously been suggested that CDKs are able to positively regulate cell cycle progression via phosphorylating $\mathrm{Rb}(6)$. $\mathrm{Rb}$ phosphorylation induces the release of E2F in late G1 stage, which in turn enhances the expression of genes 
that encode the regulatory proteins necessary for cell cycle progression (8). Restriction of cells at the G1-S and G2-M interphases ensure normal cell cycle progression (21). In the present study, it was demonstrated that CDK4, CDK6, and $\mathrm{p}-\mathrm{Rb}$ protein levels are elevated in CSE-treated HAOSMCs. Furthermore, silencing P16 expression increased cell proliferation rate, whereas overexpression of $\mathrm{P} 16$ induced a decrease in cell proliferation rate, cell cycle progression, and the expression of CDK4, CDK6, and p-Rb protein.

In conclusion, the results of the present study suggest that CSE is able to downregulate P16 expression in HAOSMCs by inducing hypermethylation of its promoter, which promotes VSMC proliferation via activating the CDK/p-Rb pathway, preventing cell cycle progression from G1 to $\mathrm{S}$ phase. These findings may provide a new insight for cigarette smoking-induced VSMC proliferation.

\section{Acknowledgements}

The present study was supported by the National Nature Science Foundation of China (grant no. 81471896) and Hunan Science Foundation (grant no. 10JJ5008).

\section{References}

1. Ezzati M, Henley SJ, Thun MJ and Lopez AD: Role of smoking in global and regional cardiovascular mortality. Circulation 112: 489-497, 2005.

2. Ambrose JA and Barua RS: The pathophysiology of cigarette smoking and cardiovascular disease: An update. J Am Coll Cardiol 43: 1731-1737, 2004.

3. Burns DM: Epidemiology of smoking-induced cardiovascular disease. Prog Cardiovasc Dis 46: 11-29, 2003.

4. Hao H, Gabbiani G and Bochaton-Piallat ML: Arterial smooth muscle cell heterogeneity: Implications for atherosclerosis and restenosis development. Arterioscler Thromb Vasc Biol 23: $1510-1520,2003$

5. Dzau VJ, Braun-Dullaeus RC and Sedding DG: Vascular proliferation and atherosclerosis: New perspectives and therapeutic strategies. Nat Med 8: 1249-1256, 2002.

6. Sherr CJ and Roberts JM: CDK inhibitors: Positive and negative regulators of G1-phase progression. Genes Dev 13: 1501-1512, 1999.

7. Malumbers $\mathrm{M}$ and Barbacid M: To cycle or not to cycle: A critical decision in cancer. Nat Rev Cancer 1: 222-231, 2001.

8. Burke JR, Hura GL and Rubin SM: Structures of inactive retinoblastoma protein reveal multiple mechanisms for cell cycle control. Genes Dev 26: 1156-1166, 2012.
9. Witkiewicz AK, Knudsen KE, Dicker AP and Knudsen ES: The meaning of p16(ink4a) expression in tumors: Functional significance, clinical associations and future developments. Cell Cycle 10: 2497-2503, 2011.

10. Rodriguez-Menocal L, Pham SM, Mateu D, St-Pierre M, Wei Y, Pestana I, Aitouche A and Vazquez-Padron RI: Aging increases p16 INK4a expression in vascular smooth-muscle cells. Biosci Rep 30: 11-18, 2019.

11. Gizard F, Amant C, Barbier O, Bellosta S, Robillard R, Percevault F, Sevestre H, Krimpenfort P, Corsini A, Rochette J, et al: PPAR alpha inhibits vascular smooth muscle cell proliferation underlying intimal hyperplasia by inducing the tumor suppressor p16INK4a. J Clin Invest 115: 3228-3238, 2005.

12. Holdt LM and Teupser D: Recent studies of the human chromosome 9p21 locus, which is associated with atherosclerosis in human populations. Arterioscler Thromb Vasc Biol 32: 196-206, 2012.

13. Holdt LM, Sass K, Gäbel G, Bergert H, Thiery J and Teupser D: Expression of Chr9p21 genes CDKN2B (p15(INK4b)), CDKN2A (p16(INK4a), p14(ARF)) and MTAP in human atherosclerotic plaque. Atherosclerosis 214: 264-270, 2011.

14. Yao Q, Xu H, Zhang QQ, Zhou H and Qu LH: MicroRNA-21 promotes cell proliferation and down-regulates the expression of programmed cell death 4 (PDCD4) in HeLa cervical carcinoma cells. Biochem Biophys Res Commun 388: 539-542, 2009.

15. Ou H, Shen YH, Utama B, Wang J, Wang X, Coselli J and Wang XL: Effect of nuclear actin on endothelial nitric oxide synthase expression. Arterioscler Thromb Vasc Biol 25: 2509-2514, 2005

16. Motterle A, Pu X, Wood H, Xiao Q, Gor S, Ng FL, Chan K, Cross F, Shohreh B, Poston RN, et al: Functional analyses of coronary artery disease associated variation on chromosome 9 p21 in vascular smooth muscle cells. Hum Mol Genet 21: 4021-4029, 2012

17. Ghiorzo P, Villaggio B, Sementa AR, Hansson J, Platz A, Nicoló G, Spina B, Canepa M, Palmer JM, Hayward NK and Bianchi-Scarrà G: Expression and localization of mutant p16 proteins in melanocytic lesions from familial melanoma patients. Hum Pathol 35: 25-33, 2004.

18. LaPak KM and Burd CE: The molecular balancing act of p16(INK4a) in cancer and aging. Mol Cancer Res 12: 167-183, 2014.

19. Zhuang J, Peng W, Li H, Wang W, Wei Y, Li W and Xu Y: Methylation of p15INK4b and expression of ANRIL on chromosome 9 p21 are associated with coronary artery disease. PLoS One 7: e47193, 2012.

20. Miki K, Shimizu E, Yano S, Tani K and Sone S: Demethylation by 5-aza-2'-deoxycytidine (5-azadC) of p16INK4A gene results in downregulation of vascular endothelial growth factor expression in human lung cancer cell lines. Oncol Res 12: 335-342, 2001.

21. Elledge SJ: Cell cycle checkpoints: Preventing an identity crisis. Science 274: 1664-1672, 1996. 